\title{
A scoping study of the application of neutral beam heating on the TCV tokamak
}

\author{
Alexander N. Karpushov a,*, Basil P. Duval ${ }^{a}$, René Chavan ${ }^{\mathrm{a}}$, Emiliano Fable $^{\mathrm{b}}$, Jean-Michel Mayor ${ }^{\mathrm{a}}$, \\ Olivier Sauter $^{\mathrm{a}}$, Henri Weisen ${ }^{\mathrm{a}}$
}

a Ecole Polytechnique Fédérale de Lausanne (EPFL), Centre de Recherches en Physique des Plasmas, Association Euratom-Confédération Suisse, CH-1015 Lausanne, Switzerland

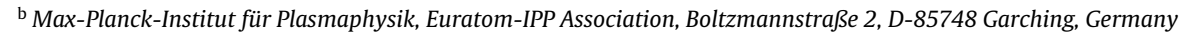

\section{A R T I C L E I N F O}

\section{Article history:}

Available online $\mathrm{xxx}$

\section{Keywords:}

TCV tokamak

Neutral beam heating

\begin{abstract}
A B S T R A C T
The TCV tokamak contributes to the physics understanding of fusion plasmas, broadening the parameter range of reactor relevant regimes, by investigations based on an extensive use of the existing main experimental tools: flexible shaping and high power real time-controllable electron cyclotron heating $(\mathrm{ECH})$ and current drive (ECCD) systems. A proposed implementation of direct ion heating on the TCV by the installation of a $20-35 \mathrm{keV}$ neutral beam injection (NBI) with a total power of 1-3 MW would permit an extension of the accessible range of ion to electron temperatures $\left(T_{\mathrm{i}} / T_{\mathrm{e}} \sim 0.1-0.8\right)$ to well beyond unity, depending on the NBI/ECH mix and the plasma density. A NBI system would provide TCV with a tool for plasma study at reactor relevant $T_{\mathrm{i}} / T_{\mathrm{e}}$ ratios $\sim 1$ and in investigating fast ion and MHD physics together with the effects of plasma rotation and high plasma $\beta$ scenarios. The feasibility studies for a NBI heating on TCV presented in this paper were undertaken to construct a specification for the neutral beam injectors together with an experimental geometry for possible operational scenarios.
\end{abstract}

(C) 2011 ASSOCIATION EURATOM, Confederation Suisse, EPFL CRPP. Published by Elsevier B.V. All rights reserved.

\section{Introduction}

TCV is a compact (major radius $R=0.88 \mathrm{~m}$, minor radius $a \leq 0.25 \mathrm{~m}$, toroidal magnetic field $B_{\mathrm{T}} \leq 1.54 \mathrm{~T}$, plasma current of $I_{\mathrm{p}} \leq 1 \mathrm{MA}$ ), high elongated (vessel elongation 3 ) toroidal fusion experimental machine. High power, real-time controllable, injection of waves at the second (X2, $3 \mathrm{MW}$ ) and third (X3, 1.5 MW) harmonics of electron cyclotron frequency constitute the primary method of heating $(\mathrm{ECH})$ and driving non-inductive current (ECCD) in the plasma with electron densities $0.7 \leq n_{\mathrm{e}}(0) \leq 15 \times 10^{19} \mathrm{~m}^{-3}$, electron temperatures $0.3 \leq T_{\mathrm{e}}(0) \leq 15 \mathrm{keV}$, ion temperatures $0.15 \leq T_{\mathrm{i}}(0) \leq 1 \mathrm{keV}$. The flexible plasma shaping and powerful $\mathrm{ECH}$ system are used to contribute in many areas of tokamak research [1].

High power X2-ECH, for relatively low density TCV plasmas, does not allow operation at reactor relevant ratios of ion to electron temperatures $\left(T_{\mathrm{i}} / T_{\mathrm{e}} \sim 1\right)$, as the electron-ion classical Coulomb collision thermal equilibration time is significantly longer than the characteristic confinement times. Implementation of direct ion heating at the MW power level would allow the extension of $T_{\mathrm{i}} / T_{\mathrm{e}}$ to beyond unity and fill the gap between present predominantly

\footnotetext{
* Corresponding author. Tel.: +41 21693 3467; fax: +41 216935176 .

E-mail address: alexander.karpushov@epfl.ch (A.N. Karpushov).
}

electron heated experiments and fusion reactor [2]. The ion to electron temperature ratio is of particular interest in the projection of the transport mechanisms from existing experiments to burning plasma. The $T_{\mathrm{i}} / T_{\mathrm{e}}$ ratio plays a key role in the transition between ion temperature gradient (ITG) and trapped electron (TEM) mode dominated turbulent energy transport mechanisms. Increasing $T_{\mathrm{i}} / T_{\mathrm{e}}$ reduces the ion and electron energy transport as observed in DIII-D H-mode experiments [3]. NBI heating may therefore allow TCV plasmas to reach higher $\beta$ values, close to the ideal limit or beyond at high elongation.

Injection of fast atom beams (NBI) into tokamak is a possible and well used method of auxiliary heating. Following ionisation and charge-exchange, fast atoms of the beam are trapped as plasma ions and transport energy and momentum mainly to bulk ions if the fast ion energy is below critical energy $\left(E_{\text {crit }} \sim 20 \mathrm{keV}\right.$ for hydrogen beam and deuterium plasma, $\left\langle T_{\mathrm{e}}\right\rangle=1 \mathrm{keV}$ ) [4]. The proposed NBI system would thus also provide TCV with a tool to investigate fast ion and related MHD physics [5] as well as plasma rotation control [6] for which TCV is already well diagnosed. The behaviour of toroidal rotation in the vicinity of an ITB is of particular interest because of its influence on triggering and/or sustaining the barrier. Target plasmas could include ITER-like H-mode shapes together with advanced shapes, recently accessible only in ohmic regimes [7]. 
D, 25keV,tang.,CO-Ip NB power scan for ELMy H-mode

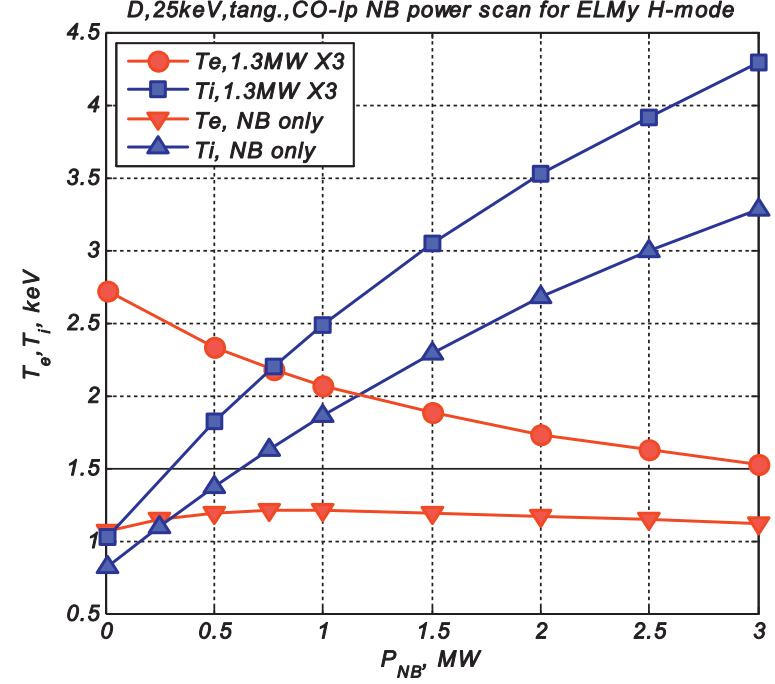

Fig. 1. Electron and ion temperatures vs NB power for ELMy H-mode without and with 1.3 MW X3-EC heating.

\section{Scenarios of NBI heating experiments}

Experimental scenarios for the NBI experiments on the TCV are strongly linked to limitations imposed by ECH and ECCD. For the eITBs and fully non-inductive scenarios on TCV, the accessible plasma density is limited by the X2 cut-off $\left(n_{\mathrm{e}}<4 \times 10^{19} \mathrm{~m}^{-3}\right)$ in current drive and electron heating experiments. Conversely, efficient X3 deposition is obtained for electron density in the range of $5.0-7.5 \times 10^{19} \mathrm{~m}^{-3}$ and $T_{\mathrm{e}}>2 \mathrm{keV}$.

The ASTRA code [8] was used to simulate the plasma response to neutral beam heating in the geometry of the TCV tokamak. The code solves equations for electron and ion temperature and plasma current density with the prescribed electron density profile and total plasma current taken from TCV experiment. The use of the neoclassical ion heat conductivity $\left(\chi_{\mathrm{i}}\right)$ [9] gives $T_{\mathrm{i}}(\rho)$ that is matched to the CXRS [10] measurement. The experimental electron heat conductivity $\left(\chi_{e}\right)$ was normalised to obtain the energy confinement time predicted by power law scalings [11]: IPB98 $(y, 2)$ for ELMy $\mathrm{H}$-mode and standard power law regression for L-mode. The EC power deposition profile was calculated by the TORAY ray-tracing code.

\subsection{High density ELMy $H$-mode regime}

The target parameters for modelling were taken from Ohmic and X3 heated (Table 1, No. 1.0) stationary ELMy H-mode phases of TCV discharge [12]. About $95 \%$ of injected $25 \mathrm{keV}$ deuterium NB power can be absorbed by the plasma for tangentially injected beam. The simulations show that $T_{\mathrm{i}}(0)=T_{\mathrm{e}}(0) \cong 2.2 \mathrm{keV}$ can be achieved with $\sim 0.8 \mathrm{MW}$ of NBI and 1.3 MW X3-ECH (Figs. 1 and 2). Access to $T_{\mathrm{i}} / T_{\mathrm{e}}>2$ should be attainable at increased ( $\geq 2 \mathrm{MW}$ ) NB or reduced X2-ECH power. The fast ion charge-exchange (CX) losses on background neutrals strongly depend on the first wall recycling conditions, the density of background atoms $n_{0} \mathrm{D}(\mathrm{LCS})=5 \times 10^{15} \mathrm{~m}^{-3}$, obtained from EIRENE modelling, reduces the NB heating efficiency by $\sim 15 \%$ (No. 1.4), CX losses on beam neutrals $(\leq 2 \%)$ are neglectable.

At high plasma density and current, neutral beam injection could result in an increase of the thermal $\beta_{\mathrm{N}}$ from 2.0 (pure $1.5 \mathrm{MW}$ $\mathrm{X} 3-\mathrm{ECH})$ to 2.6 (2 MW NBI), and could even reach the ideal MHD $\beta$ limit $(\sim 3)$ resulting from the fast particle contribution. Fast ion slowing down times in such regimes are of the order of $10 \mathrm{~ms}$, i.e. shorter or comparable with the bulk plasma energy confinement

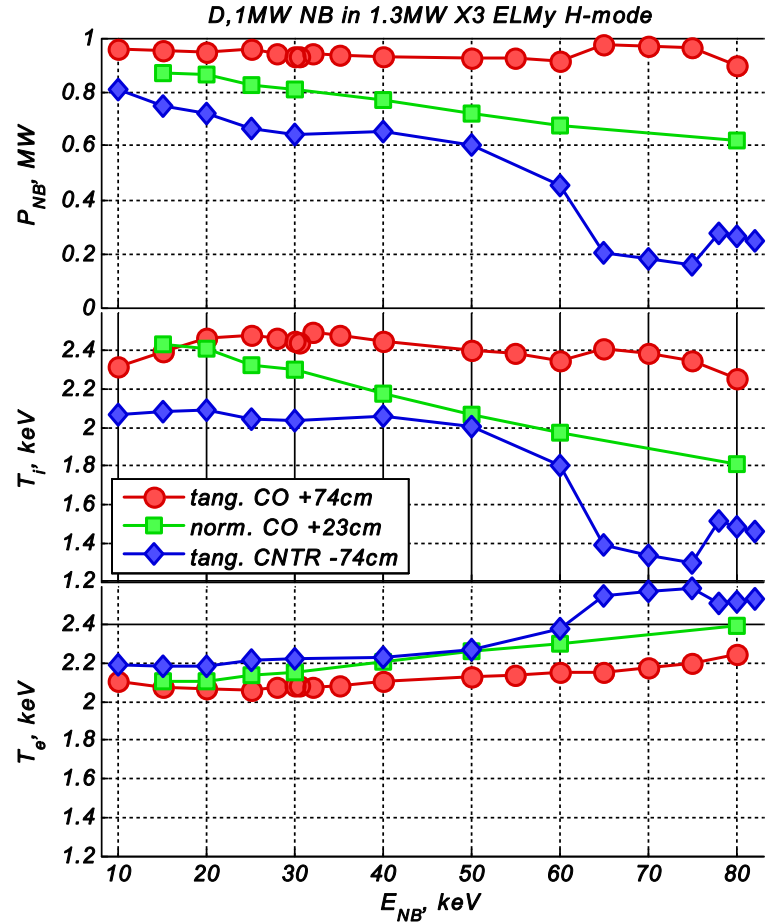

Fig. 2. NB heating vs $E_{\mathrm{NB}}$ in $\mathrm{H}$-mode for tangential co- and counter- $I_{\mathrm{p}}$ and normal co- $I_{\mathrm{p}}$ injection.

time ( $\tau_{\mathrm{E}}, 10-50 \mathrm{~ms}$ ) so, perturbation of the ion energy Maxwellian distribution by fast ions is expected to be small (as in a fusion reactor).

\subsection{X2-EC and NBI heating}

Modelling of NB heating in low density regimes was performed for 2 MW X2-EC heated L-mode reference discharge (\#31761, No. 2.0). Increase of the NB deposited power per plasma ion at low density results in $\sim 2$ times lower $(\leq 0.5 \mathrm{MW})$ than in high density regime NBI power required to access $T_{\mathrm{i}}(0)$ of $2-3 \mathrm{keV}$ (scenarios 2.1 and 2.2 and Fig. 3). Near-normal NB injection ( $\left.E_{\mathrm{NB}} \geq 15 \mathrm{keV}\right)$ cannot be considered here due to higher $(>20 \%)$ shine-through losses, resulting in first wall overheat of the TCV central column. ASTRA simulations confirm earlier experimental and numerical studies of fast ion orbit losses on the TCV [13]. At low plasma current, fast ion orbit losses are extremely important and become substantial for counter- $I_{\mathrm{p}}$ NB injection (Fig. 4); losses increase at high ion energy (32\% for $25 \mathrm{keV}$ D-NB and 59\% for $50 \mathrm{keV}$, scenarios 2.4 and 2.7 ) and for higher NB atomic mass.

NB injection at low plasma density and current provides the possibility to study the fast ion and MHD physics. In the unfavourable scenario (like 2.4), the $200-300 \mathrm{~kW}$ delivered by the NB power leads to the creation of a strong fast ion population with a stored energy of few tens kJ that, at low current, significantly contributes to the ideal MHD $\beta$ limit. Fast particle instabilities would dominate the plasma behaviour under these conditions [5].

\section{Neutral beams injection layout}

TCV was not originally designed for neutral beam heating although several relatively wide machine midplane lateral ports were implemented for general diagnostic flexibility. The location of magnetic field coils, for which modification is not feasible, and the existing support structures are major problems for NBI plasma access, in particular for the tangential injection direction. Access for 
Table 1

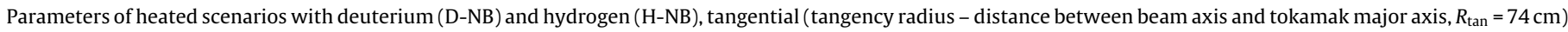

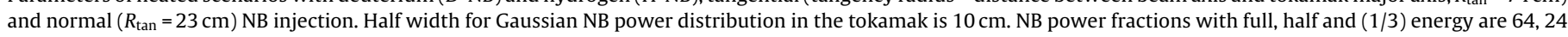

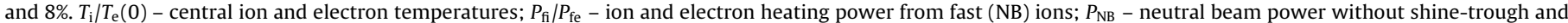

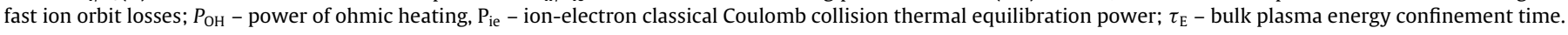

\begin{tabular}{|c|c|c|c|c|c|c|}
\hline No. & Scenario/parameter & $T_{\mathrm{i}} / T_{\mathrm{e}}(0)(\mathrm{keV})$ & $P_{\mathrm{fi}} / P_{\mathrm{fe}}(\mathrm{kW})$ & $P_{\mathrm{NB}} / P_{\mathrm{OH}}(\mathrm{kW})$ & $P_{\text {ie }}(\mathrm{kW})$ & $\tau_{\mathrm{E}}(\mathrm{ms})$ \\
\hline \multicolumn{7}{|c|}{ ELMy H-mode with $1.5 \mathrm{MW} X 3 \mathrm{ECH}, \mathrm{n}_{e}(0)=7.8 \times 10^{19} \mathrm{~m}^{-3}, \mathrm{I}_{p}=406 \mathrm{kA}, \mathrm{X} 3$-ECH deposited power $\sim 1.3 \mathrm{MW}$} \\
\hline 1.0 & TCV\#29475 at $1.0-1.3 \mathrm{~s}$ (reference, X3) & $1.02 / 2.72$ & $0 / 0$ & $0 / 210$ & -183 & 25.5 \\
\hline 1.1 & $0.77 \mathrm{MW}, 25 \mathrm{keV}, \mathrm{D}-\mathrm{NB}, \mathrm{CO}-\mathrm{I}_{\mathrm{p}}$, tangential & $2.20 / 2.18$ & $630 / 100$ & $741 / 248$ & 187 & 19.3 \\
\hline 1.2 & $1.00 \mathrm{MW}, 25 \mathrm{keV}, \mathrm{D}-\mathrm{NB}, \mathrm{CO}-\mathrm{I}_{\mathrm{p}}$, tangential & $2.48 / 2.06$ & $803 / 138$ & $957 / 258$ & 298 & 18.2 \\
\hline 1.3 & $2.00 \mathrm{MW}, 25 \mathrm{keV}, \mathrm{D}-\mathrm{NB}, \mathrm{CO}-I_{\mathrm{p}}$, tangential & $3.53 / 1.73$ & $1500 / 319$ & $1883 / 303$ & 767 & 14.7 \\
\hline 1.4 & No. 1.2 with CX losses, $n_{0} \mathrm{D}(\mathrm{LCS})=5 \times 10^{15} \mathrm{~m}^{-3}$ & $2.35 / 2.17$ & $706 / 113$ & $957 / 245$ & 228 & 19.2 \\
\hline 1.5 & 1.00 MW, $25 \mathrm{keV}, \mathrm{D}-\mathrm{NB}, \mathrm{CNTR}-I_{\mathrm{p}}$, tangential & $2.05 / 2.21$ & $578 / 74$ & $663 / 245$ & 152 & 19.8 \\
\hline 1.6 & $1.00 \mathrm{MW}, 25 \mathrm{keV}, \mathrm{D}-\mathrm{NB}, \mathrm{CO}-\mathrm{I}_{\mathrm{p}}$, normal & $2.33 / 2.14$ & $697 / 110$ & $823 / 251$ & 225 & 18.9 \\
\hline 1.7 & $1.00 \mathrm{MW}, 25 \mathrm{keV}, \mathrm{H}-\mathrm{NB}, \mathrm{CO}-\mathrm{I}_{\mathrm{p}}$, tangential & $2.40 / 2.20$ & $683 / 262$ & $963 / 242$ & 216 & 18.2 \\
\hline \multicolumn{7}{|c|}{ L-mode with $2 \mathrm{MWX} 2 \mathrm{ECH}, n_{e}(0)=2.8 \times 10^{19} \mathrm{~m}^{-3}, I_{p}=226 \mathrm{kA}$} \\
\hline 2.0 & TCV\#31761 at $0.8-1.3$ s (reference, $\mathrm{X} 2$ ) & $0.75 / 4.21$ & $0 / 0$ & $0 / 31$ & -52 & 7.9 \\
\hline 2.1 & $0.30 \mathrm{MW}, 25 \mathrm{keV}, \mathrm{D}-\mathrm{NB}, \mathrm{CO}-\mathrm{I}_{\mathrm{p}}$, tangential & $2.87 / 2.46$ & $218 / 44$ & $278 / 69$ & 75 & 7.2 \\
\hline 2.2 & $0.50 \mathrm{MW}, 25 \mathrm{keV}, \mathrm{D}-\mathrm{NB}, \mathrm{CO}-\mathrm{I}_{\mathrm{p}}$, tangential & $3.59 / 2.00$ & $337 / 92$ & $457 / 92$ & 158 & 6.8 \\
\hline 2.3 & $1.00 \mathrm{MW}, 25 \mathrm{keV}, \mathrm{D}-\mathrm{NB}, \mathrm{CO}-\mathrm{I}_{\mathrm{p}}$, tangential & $4.52 / 1.51$ & $585 / 232$ & $909 / 130$ & 329 & 6.0 \\
\hline 2.4 & $0.50 \mathrm{MW}, 25 \mathrm{keV}, \mathrm{D}-\mathrm{NB}, \mathrm{CNTR}-I_{\mathrm{p}}$, tangential & $3.31 / 2.31$ & $235 / 31$ & $298 / 76$ & 89 & 7.2 \\
\hline 2.5 & $0.50 \mathrm{MW}, 25 \mathrm{keV}, \mathrm{H}-\mathrm{NB}, \mathrm{CO}-I_{\mathrm{p}}$, tangential & $3.41 / 2.21$ & $258 / 157$ & $457 / 82$ & 121 & 6.8 \\
\hline 2.6 & $0.50 \mathrm{MW}, 50 \mathrm{keV}, \mathrm{D}-\mathrm{NB}, \mathrm{CO}-I_{\mathrm{p}}$, tangential & $2.95 / 2.48$ & $243 / 110$ & $403 / 70$ & 93 & 7.2 \\
\hline 2.7 & $0.50 \mathrm{MW}, 50 \mathrm{keV}, \mathrm{D}-\mathrm{NB}, \mathrm{CNTR}-I_{\mathrm{p}}$, tangential & $1.81 / 3.35$ & $85 / 7$ & $107 / 45$ & -10 & 7.7 \\
\hline
\end{tabular}

NB injectors through $15 \mathrm{~cm}$ diameter ports with near normal injection (tangency radius $R_{\tan } \leq 23 \mathrm{~cm}$ ) and through a single $\varnothing 10 \mathrm{~cm}$ aperture near-tangential injection port with the axis passing near the inner wall at $R_{\tan } \cong 65 \mathrm{~cm}$ has been analysed in [13]. Shine through for $R_{\text {tan }} \cong 23 \mathrm{~cm}$ is workable at the high densities; NB usage at low densities is, however, severely limited by excessive shinethrough and high inner wall power loads. The maximal acceptable power load of $7.6 \mathrm{MW} / \mathrm{m}^{2}$ for a $1 \mathrm{~s}$ duration leads to temperature rise of graphite inner wall tiles [14] of $1000 \mathrm{~K}$ corresponding to $\sim 10 \%$ shine-through of the $1 \mathrm{MW}$ beam with the $15 \mathrm{~cm}$ foot-print size.

A model of a neutral beam with geometric focussing and angular divergence [15] was performed to calculate the beam transmission and power load on the critical scrapers in the NBI duct. The acceptable $\sim 80 \%$ beam power transmitted into the tokamak for $1 \mathrm{MW}, 25 \mathrm{keV}, 1 \mathrm{~s}$ beam with $200 \mathrm{~mA} / \mathrm{cm}^{2}$ extraction current from the ion optical system located at about $250 \mathrm{~cm}$ from the TCV port is feasible only with low beam divergence: $0.7 / 0.8^{\circ}$ for $\emptyset 10 / 15 \mathrm{~cm}$ duct apertures respectively. The transmission of the high power (0.6-1.0 MW) NB through narrow ports demands high current density, low divergence neutral beam injector only reachable, at present, by lower current diagnostic neutral beams.

To allay these requirements on beam divergence and current density a modification TCV vacuum vessel to create new port(s), specifically designed for NBH and fitted between magnetic field coils, is considered. The available gaps between toroidal and poloidal magnetic field coils at the TCV midplane are $22 \mathrm{~cm}$ in vertical and $38 \mathrm{~cm}$ in toroidal direction. The design of duct with inner

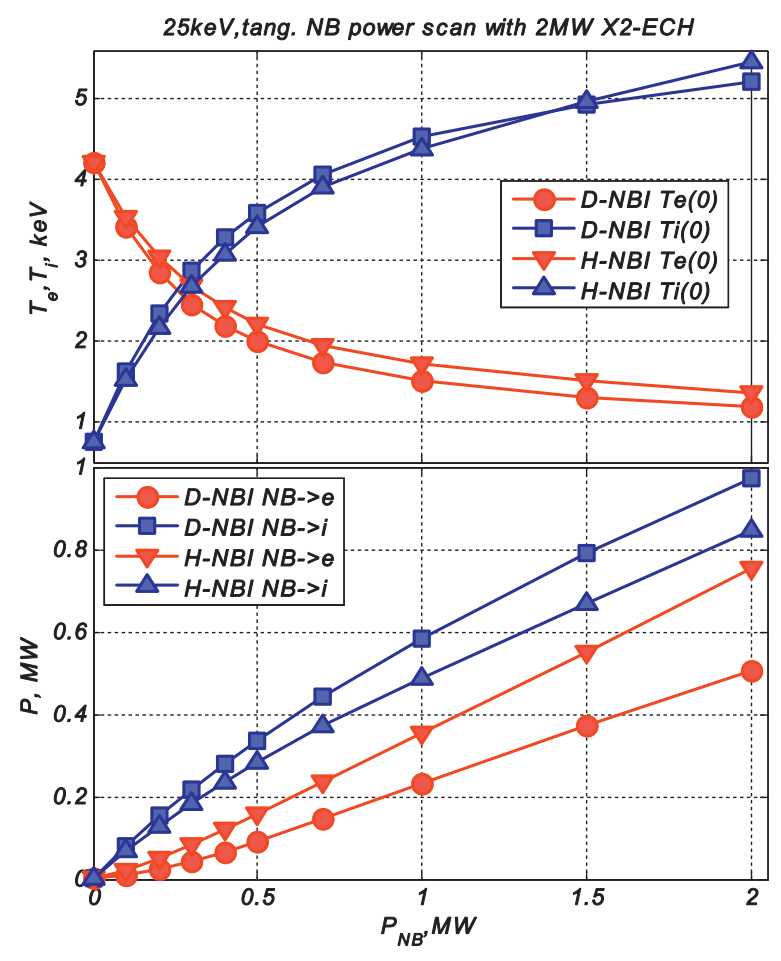

Fig. 3. Deuterium and hydrogen NB heating for L-mode with $2 \mathrm{MW} X 2-\mathrm{EC}$ heating.

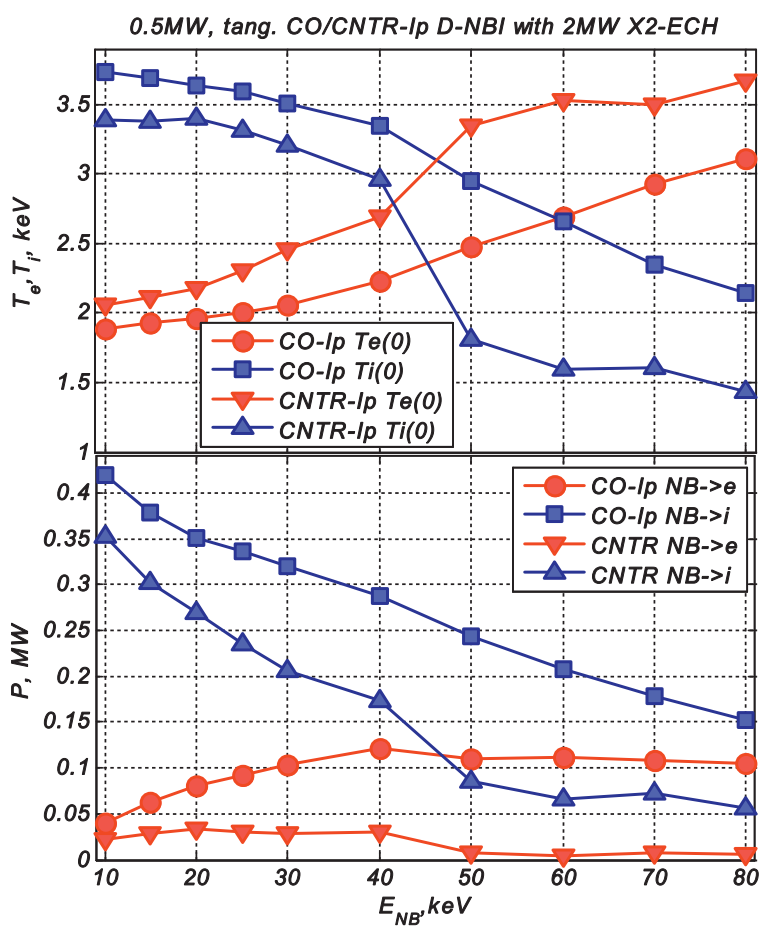

Fig. 4. Co- and counter- $I_{\mathrm{p}} \mathrm{NB}$ heating vs $E_{\mathrm{NB}}$ in L-mode. 


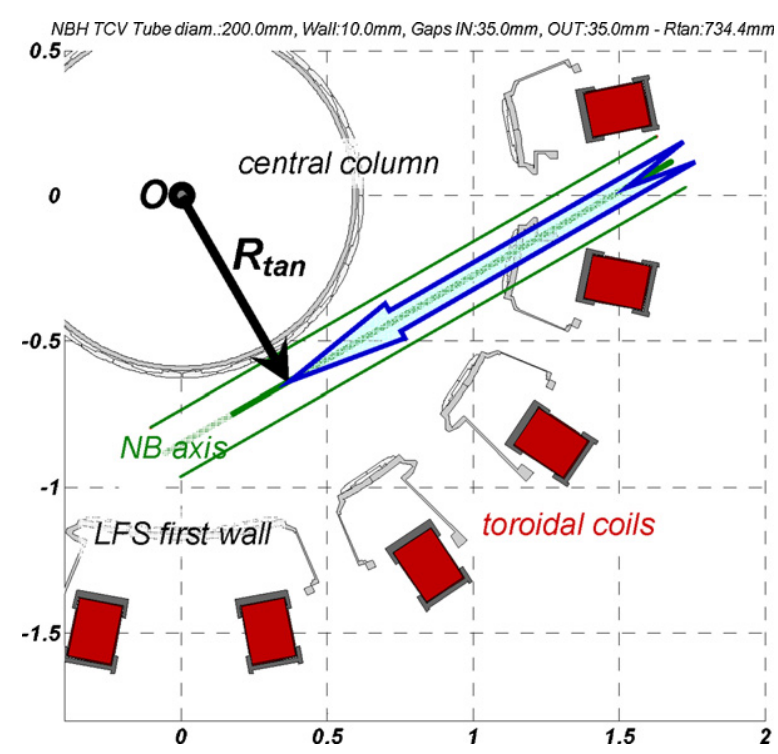

Fig. 5. Tangential injection arrangement for modification of vacuum vessel.

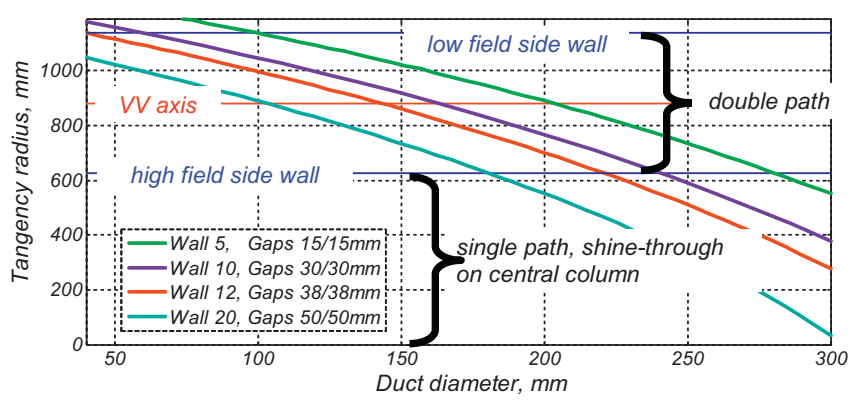

Fig. 6. NB tangency radius vs maximal beam duct diameter.

minimal aperture of $20 \mathrm{~cm}$, wall thickness $1 \mathrm{~cm}$ and $3 \mathrm{~cm}$ gaps to toroidal field coils, beam axis tangency radius of $74 \mathrm{~cm}$ (Fig. 5) was found to be feasible and permits to transmit $>90 \%$ of the NB power to the plasma for $1 \mathrm{MW}, 25 \mathrm{keV}$ deuterium beam with divergence $\leq 1.2^{\circ}$ (reachable for heating beams). The relation between $R_{\tan }$ and beam duct aperture horizontal size for chosen duct wall thickness and gaps to toroidal coils is shown in Fig. 6. To reduce beam blocking by desorbed gas in the narrowest part of the beam duct (close to the tokamak entrance), differential duct pumping is required. This geometry could permit two NB injectors (aiming in co- and counter-current directions) on the same port. With proper power adjustment, one could obtain scenarios with balanced momentum transfer to the plasma.

\section{Conclusion}

Installation of $1 \mathrm{MW}, 25 \mathrm{keV}$, deuterium, tangential (basic reference) neutral beam injector would significantly increase the experimental capability of the TCV tokamak by extending the operational domain at higher $T_{\mathrm{i}} / T_{\mathrm{e}}$ ratio and plasma pressure $(\beta)$ and widening $\mathrm{H}$-mode operational domain (especially at high density). $1 \mathrm{MW}$ of injected power is sufficient to access $T_{\mathrm{i}}=T_{\mathrm{e}} \geq 2 \mathrm{keV}$, taking into account $20 \%$ CX fast ion losses on background neutrals. Two balanced co- and counter- $I_{\mathrm{p}}$ orientated injectors with total power of $2 \mathrm{MW}$ would permit the investigation of the effects of NB induced plasma rotation, to reach $T_{\mathrm{i}} / T_{\mathrm{e}}$ ratio $\geq 2$ and study fast ion behaviour and MHD physics in scenarios such as stationary ELM free $\mathrm{H}$-modes and fully non-inductive electron internal transport barriers. Lowering the beam energy results in a decrease of the on-axis ion heating power density by broadening the NB deposition profile. At higher beam energies, fast ion orbit losses strongly reduce the heating efficiency, especially for counter- $I_{p}$ beam alignment (Figs. 2 and 4). For a given injection energy and target plasma parameters, the fraction of NB power delivered to bulk ions is higher and shine-trough losses are lower for deuterium beam than for hydrogen (Fig. 4). Due to unacceptable shine-through power load on the central column, only double-path tangential NB injection is acceptable for intermediate and low plasma densities $\left(<4 \times 10^{19} \mathrm{~m}^{-3}\right.$, for $25 \mathrm{keV}$ deuterium beam).

The capability of the NBI operation to use hydrogen ions is essential (1) for on-axis ion heating at high $\left(\geq 10^{20} \mathrm{~m}^{-3}\right)$ plasma density and (2) to reduce orbit losses of counter- $I_{\mathrm{p}}$ injected fast ions at low $(<200 \mathrm{kA})$ plasma current. Adjustable beam energy of $15-30 \mathrm{keV}$ and likely a wider range should satisfy the concept of TCV a very flexible tokamak and permits to adjust beam power by simultaneous change of beam energy and ion current (maintaining optimal perveance, relationship between beam energy and current).

\section{Acknowledgments}

This work was supported in part by the Swiss National Science Foundation. The authors are grateful to Prof. A.A. Ivanov, Prof. V.I. Davydenko and Dr. T.D. Akhmetov for useful discussions and developing of the neutral-beam propagation code [15].

\section{References}

[1] A. Fasoli, Nucl. Fusion 49 (2009) 104005

[2] E.J. Doyle, et al., Nucl. Fusion 47 (2007) S18

[3] C.C. Petty, et al., Phys. Rev. Lett. 83 (1999) 3661.

[4] T.H. Stix, Plasma Phys. 14 (4) (1972) 367.

[5] A. Fasoli, et al., Nucl. Fusion 47 (2007) S264.

[6] B.P. Duval, et al., Phys. Plasmas 15 (2008) 056113

[7] Y.R. Martin, et al., Plasma Phys. Control. Fusion 45 (2003) A351.

[8] G.V. Pereverzev, P.N. Yushmanov, ASTRA, (IPP-Garching) Report 5/98 (2002).

[9] C. Angioni, O. Sauter, Phys. Plasmas 7 (2000) 1224.

[10] B.P. Duval, et al., Plasma Phys. Control. Fusion 49 (2007) B195

[11] ITER Physics Expert Group on Confinement, et al., Nucl. Fusion 39 (1999) 2175 (Section 6.3).

[12] L. Porte, et al., Nucl. Fusion 47 (2007) 952.

[13] A.N. Karpushov, et al., Proc. 36th EPS Conf. on Plasma Phys. (Europhysics Conference Abstracts vol. 33E) P-2.140, 2009.

[14] R.A. Pitts, R. Chavan, J.-M. Moret, Nucl. Fusion 39 (1999) 1433.

[15] T.D. Akhmetov, V.I. Davydenko, A.A. Ivanov, IEEE Trans. Plasma Sci. 36 (4) (2008) 1545-1551. 